\title{
The Influence of Health Education on the Physical Exercise Behavior of College Students
}

\author{
Youfeng Wang \\ Sports Department of Oxbridge College, Kunming University of Science and Technology, Kunming, \\ Yunnan 650106
}

Keywords: Physical education; College students; Physical exercise behavior; Influence

\begin{abstract}
In order to study and have a deep knowledge of the influence of health education on the high-school students' physical exercise, this article uses intervention and questionnaire methods to analyze the relationship between health education and physical exercise. By the results of comparison, colleges should reform physical education deeply and take it to implement, raising the level of ideological consciousness in physical exercise among high-school students.
\end{abstract}

\section{Background of Research}

With the development and progress of quality education, the importance of physical education process is highlighted, after analyzing the data in physical quality and health from 2000 to 2017 which our sports department did among students, although the comprehensive physical quality of college students has raised, there still are many issues, especially, and positive change remains lagging. In some fields, their physical quality is worse than middle school students and that is really a cursing problem for the educators. The reason is that these students lack consciousness in physical exercise, their exercise frequency id also not very high. Basing on this, high school should train the habits in physical exercise of college students and build a more comprehensive intervention system. While promote exercise consciousness, they could also make sure the efficiency of exercise and educational system, which will lead students to a better study habits and improve the comprehensive level.

\section{Research Method}

Basing on the analysis of college students physical educational system, it is needed to build a high-efficiency supervision and administration method. This article uses intervention method to lead the subjects and then decide which strategy is more effect. This article also uses questionnaire to collect related date and do the systematic analysis on specific conditions.

Intervention Method. According to the aim of practice, while ensure the specific content of intervention method, college should combine three basic systems as class teaching, individual consult and sports plan, thus to build effect systematic analysis. Intervention uses class teaching to do the systematic analysis on the learning progress of health education among college students, it picked the results that these students who took health education class from March 2017 to June 2017 as sample, time lasts 4 months, the learning hour in a week is 2 and thus the total learning hour in a semester is $32^{[1]}$. In the teaching experiment project, the main task is to teach different health education with modularization way, and while integrating teaching method, it is also needed to analyze study progress and idea of students. In the practical teaching curriculum, it covers a wide field, including: a)basic health education knowledge, such as sports and basic health, health exercise of college students and emergency. b)special health education knowledge, relationships such as sports and obesity, sports and beauty, sports and chronic disease and so, c) academic health education knowledge, such as fitness and health monitoring, sports hygiene, duty supervision and so on. Teachers should lead students from different fields, and they could make use of multimedia interactive teaching method to build a teaching framework system which places students as main character in class. While teaching, teachers should organize the effect discussion with their students and play plenty related videos or projects to guide them. 
Besides, teachers could draw support from interact platform and build an effect communication relationship with students, and focus on the questions that students come up with, combining their request to carry out a more systematic teaching mechanism and process. Teachers should consider things from students' real needs, to ensure the pertinence of sport projects, meanwhile, students should report real condition of exercise to teachers, which is in order to build an effect and targeted teaching framework construction, completing the sports level and make sure that both teachers and students could have an effect teaching and learning relationship.

Questionnaire Method. In order to raise the real level of study projects, we should combine the requested system and standard, building sound systematic sports exercise excel and according to the basic features of the subjects, teachers should analyze the regularity, frequency, times and strength these basic parameter of college students' sports exercise. Teachers also need to have an effect view on real results of their health exercise consuming behavior, sports injury and normalization of first aid treatment. What deserves to be mentioned the most is that during design questionnaire we should guarantee the suggestions from experts which could increase reliability. For example, this article divides students into study group and control group, each group has 70 questionnaires, and the effect ones are $130^{[2]}$.

Method of Statistical Analysis. With the support from statistical soft, we could analyze and deal with the related data.

\section{Research Process}

After building real experiment projects, we should compare before experiment and after experiment of their exercise behaviors, and we should also analyze their behavior in consume and first aid treatment.

To Analyze Behavior of Sports Exercise. After employing intervention method, study group explains the sports health knowledge, and build related public communication platform, according to the specific issue they explain and make interaction with students which increases their enthusiasm and shape an effect interacting learning construction ${ }^{[3]}$. Besides, after intervention ,the cognition level and report rate to sports exercise of students from study group are higher than before intervention, and compare with control group, it is also has some statistic meaning.

First, we analyze times of sports exercise of college students. After having intervention to the study group, teachers lead students to follow their targeted exercise plan to take part in regular sports exercise, and the whole level will improve. It is showed that related data has obvious change, especially compare before intervention and after that.

Second, we should analyze exercise after class that college students take part in. teachers lead study group students to join after class exercise and increase the frequency from one time a week to three times a week, and then help students have a good study consciousness.

Third, we analyze exercise time and strength of college students. Teachers conduct students to shape a right cognition of sports exercise and that not mean they need a hard intensity only in one time, they should increase the times and strength gradually, in order to have a habit of exercise. Therefore, teachers also need to lead study students do special sports exercise, and ask them to do a heavy-perspiration exercise in one week ${ }^{[4]}$.

According to the experiment, we could find that compared with pre-intervention, the exercise effect of college students is better.

To Analyze Sports Consuming Behavior. Teachers lead students to aim at sports consuming items, which also reflects their healthy consciousness, while designing the curriculum, teachers should help students shape such consciousness and let them combine their own level and family condition, to practice a more reliable educational system. Basing on that, teachers need to have a multiple analysis of sports consuming behavior that before intervention and after intervention.

To Analyze Behavior of Emergency Injury Treatment. As for the practical educators, they not only need to lead students to shape consciousness of exercise, they also need to help them have an effect study system and idea gradually. With more intuitive education construction and framework, 
teacher should make sure students will have a better cognition of sports injury. According to the experiment data, the emergency treatment level of college students from study group is increase obviously, especially in the side of sports injury treatment. For example, the knowledge teachers should explain to students is including sports injury, dislocation, exercise strain, pulled muscle and so on ${ }^{[5]}$.

\section{Research Conclusion}

Results of Basic Study. According to the related data of study group and control group, it shows that teaching intervention method play a key role. Having a good habit of exercise could promote comprehensive physical and healthy level, which could create fine study circumstance to ensure students achieve their learning aim step by step. Finish study intervention projects, students in study group has more interest to take part in exercise and sports learning, they also could have a well interaction with teachers. Compared with pre-intervention, the change is bigger and it also match the basic prove of the article. Besides, among the study group, boys are increase gradually in fields of regularity and times. We could use curriculum system, individual consult mechanism and exercise prescription these method to build a complete coping measure, which will guarantee the real value of supervision and management effect, and could ensure the exercise behavior be better [6].

Besides, college students raise their cognition of exercise, changing their consuming idea as well. Students gradually shape their exercise consuming concept, and pay more attention to the healthy investment projects. As for sports emergency treatment, students in study group promote their ability of it, which means, students have shaped healthy sports learning mechanism gradually, and they also strengthen their consciousness in sports injury protection. College students could have clear cognition of sports health care and emergency things, therefore the whole education teaching will be deeply rooted in the hearts of the people.

Teaching Suggestion. While build the practical teaching mechanism, teachers should start from the need of students, making complete teaching concept and mechanism, they also need to know deeply of good changes from students and to complete teaching concept, ensuring students could stick to exercise and therefore achieve the aim of healthy education ${ }^{[7]}$.

First, integrate teaching. Teachers should integrate teaching strategy and the complete of teaching system, they should respect student in class as main character, and ensure that teaching strategy will more fit study needs of students. In the practical teaching process, teachers should build a sound systematic teaching framework positively and while maintain their educational concept, they could guarantee good interacting consciousness between teachers and students. During with the support of healthy educational teaching, teachers could increase students' cognition of sports injury protection, and bring regular education into daily sports curriculum which will ensure the integrity of sports healthy care and emergency knowledge items, therefore to improve systematic degree of sports injury. In the class, teachers could deal with some sports injury issues with proper which will match the real value, and with the help of intervention, it could increase reliability of students to their teacher. Apart from it, when taking practical teaching work, teachers should build a sound systematic teaching strategy, using video teaching and practical teaching and situational teaching as well, which could ensure students grasp related theory of health exercise, and in the meanwhile, they also shape right exercise attitude and to complete exercise behavior. All the teaching system and process should give priority to the student, teachers also need to focus on students' study need and effect, to ensure there will be more harmonious study system between teachers and students. Only lead students to shape right healthy exercise concept and cognition, further exercise behavior could be improved with its help, maintaining the integrity of teaching idea [8].

Second, integrate consuming consciousness. As for college students, teachers should pay attentions to education reform and consuming consciousness, therefore raise their learning interest fundamentally and increase their exercise enthusiasm. It also means, teachers should take the education reform deeply and combine the learning interest of students to strengthen the site 
construction, which will guarantee students' learning needs fundamentally, maintaining the integrity of teaching concept and teaching framework that offers guarantee to further teaching task and lead students to build harmonious relationship between them and teachers. It needs college to operate more effect measure in education cultural propaganda, linking curriculum content with school culture to ensure that college students will shape right consuming idea gradually. While building teaching framework and conveying sports knowledge, teachers should guide students to have complete and healthy sports value.

Third, optimize exercise environment. In order to improve the teaching construction in sports health education, teachers also need to integrate supervision and management measures and help students have related learning concept and habits when strengthening their consciousness. Apart from developing practical teaching construction, teachers also need to make use of organizational learning method to improve students' comprehensive ability. Besides, teachers should focus on the efficiency of practical class, making sure that site broadcasting, sports lecture and sports quiz will be the new regular teaching strategy, to maintain integrity of teaching framework ${ }^{[9]}$.

Forth, cultivate interest. Teachers should place students' sports interest as important teaching site when considering practical teaching concept, reforming traditional teaching code and system to build a happy sports teaching construction, they also need to integrate a class teaching and learning model which gave priority to students. In class teaching, the reason why teachers should cultivate interest of students is to build a more positive studying process, conducting students to follow teacher's teaching regular and steps. They maintain the teaching content and automatic option, and to develop social needs of students, making sure that the integrity of transformation in education will be fine, which could offer a sound base to further teaching framework. Apart from it, teachers also need to operate more sports items under schools' conditions, and to ensure that related items could give comprehensive option to students, which can maintain their optional rights. Therefore, students choose the sports items that they like according to personal interest. In the practical teaching, students use their automatic option right to match the more needed sports education ${ }^{[10]}$. Colleges should integrate their educational aims and carry out systematic teaching strategy, to suit the social features of 21 th century which could raise learning automatic and positivity of students, developing and increasing their interest in sports.

\section{Summary}

In a word, teachers should pay more attention to the sports-behavior shaping work, to promote supervision and control measure, while maintain the efficiency of management, they also need to make sure that teaching framework will fit practical request of students, which could be a sound base for further teaching work.

\section{Reference}

[1] Liu Yongmei, Zhen Xiao, Zhao Huining. Comparison of physical exercise behavior of college students based on the orientation of healthy behavior $[\mathrm{J}]$. Chinese Journal of School Health,2017(05):660-662.

[2] Ma Shen, Wang Baishan. A study on the relationship between physical activity and exercise behavior of College Students [J].Chinese Journal of Behavior Medicine and Brain Science,2014(11):1020-1022.

[3] Wu Xiaomao. Study on the influence of College Students' exercise behavior on the attitude of physical exercise [J].Journal of Chifeng University (natural science edition),2015(14):135-137.

[4] Ma Aimin. The influence of physical health assessment on the exercise behavior of College Students [J].Health education in China,2016(08):726-728.

[5] Wang Yinhu. Study on the intervention of College Students' exercise behavior and exercise effect with HAPA backgroud [J]. Journal of Hebei Institute of Physical Education,2016(04):53-60. 
[6] Li Fengying. The Influence of Health Education on the Physical Exercise Behavior of College Students [J]. Sichuan Sports Science,2017(01):129-133.

[7] Duan Fugui, Zhang Zhigang. Analysis on the Influencing Factors of Adolescent Physical Exercise Behavior [J]. Development of talent resources,2015(22):236-237.

[8] Ma Shen, Ma Yunxia, Zhu Wei. Dynamic Observation on the Effect of Phased Intervention on Physical Exercise Behavior of College Students [J]. The Science of Behavioral Medicine in China,2016(12):1106-1108.

[9] Chen Shanping. The Grade Characteristics of College Students' Physical Health and Physical Exercise Behavior [C]. The Fourteenth World mass sports conference.2015:1-2.

[10] Xie Hongguang. The Influence of Physical Health Belief on the Behavior Intention and Behavior Habit of College Students [D]. Beijing Sport University,2016. 